Boucetta Djahida

Imine Omar

http://dx.doi.org/10.21278/brod70104

ISSN 0007-215X

eISSN 1845-5859

\title{
NUMERICAL SIMULATION OF THE CAVITATING FLOW AROUND MARINE CO-ROTATING TANDEM PROPELLERS
}

UDC 629.5.016.8:629.5.03:532.528

Original scientific paper

\begin{abstract}
Summary
In the present paper, a numerical simulation has been carried out to determine the hydrodynamic characteristics in cavitating viscous flow of the conventional INSEAN E779A propeller in single and tandem configuration by using Singhal et al. cavitation model implemented in FLUENT Software. Firstly, calculations have been carried out on single E779A propeller in non-cavitating and cavitating flows. The computed performances have shown good agreement with experimental data. Next, the numerical approach has been applied in loaded conditions to the case of tandem propeller configurations with respectively 0.2 and 0.6 axial displacement. Results reveal that cavitation is qualitatively well predicted and the cavitation area is rather more pronounced on the fore propeller. Te use of tandem corotating propeller in loaded conditions is highlighted.
\end{abstract}

Key words: $\quad$ Numerical simulation; marine tandem co-rotating propellers; cavitating viscous flow; Singhal et al. cavitation model; open water performances

\section{Introduction}

Cavitation has significant impacts on marine propellers. Indeed, it causes the erosion of the blade therefore destroys the propeller. Furthermore, it can affect the efficiency and the thrust, considerably limiting the operation of propulsion system. The costs of the systems involved in the ship propulsion that might be damaged by this phenomenon are enormous. It is very difficult to avoid completely these effects but reducing it as much as possible. To do so, more attention should be given for the design phase of the propeller.

Understanding and analyzing the cavitation phenomenon has been proved to be very important for the proper design of marine propellers. The appropriate technique is coupling of experimental and numerical studies [1]. Several authors have studied the general aspect of the cavitation flows [2-5]. Some others have interested on specific aspects of cavitation flows such as: bubble formation and dynamics, erosion, acoustics associated with noise due to implosion and bubble collapse, rotating cavitation, cavitation Vortices ... etc. 
F. A. Pereira et al. [6], experimentally, studied a propeller operating in non-uniform wake. The authors establish quantitative correlations between the near-field pressure and the cavitation model that occurs on the propeller blades. Y. Chang et al. [7] carried out an experimental study on the flow around a marine propeller in a cavitation tunnel. Authors in [8] investigated the cavitation structure of the INSEAN E779A propeller in a uniform flow by using experimental velocimetry (PIV). In the work of R. Arazgaldi et al. [9] cavitation is also experimentally and numerically studied around two different types of marine propellers.

The flow around the marine propeller is known to be unsteady, highly turbulent and occasionally cavitating. The choice of propeller type for a particular propulsion application may be the result of several considerations, i.e., maximum efficiency, noise reduction, manoeuvrability, installation cost and minimization of cavitation risk.

Stefano Gaggero et al.[10] optimize the propeller design by using the multi-objective numerical approach. Authors improve the propeller efficiency and reduce the cavitation extension for high-speed craft propeller.

Computational Fluid Dynamic (CFD) might be the appropriate tools to investigate the performance of tandem co-rotating propellers and thus identifying the optimum conditions for their applications in naval propulsion. D. Boucetta and O. Imine [11] performed a numerical simulation that explores the hydrodynamic behaviour of co-rotating tandems using the RANS approach.

Qin Sun et al. [12] investigate the hydrodynamic characteristics of tandem propellers and demonstrate their range of application to ships. A simplified practical design approach has been proposed which, together with the experiments, has been helpful in assessing the importance of some propeller design parameters. Open water design charts have been produced by testing two model tandem propellers with an axial relative position less than 0.3 . The obtained results confirm that propulsive power, bollard pull and vibration levels were better than those of conventional propeller.

Authors in [13] studied the design and performance of tandem propeller device which has good cavitation characteristics. The experiments show that it is possible to design efficient tandem propellers with large number of blades and difference pitch ratio between the aft and the fore propellers greater than 0.2.

Since experimental and numerical analysis, devoted to this type of thrusters, especially those dealing with the cavitation problem, are very scarce and less detailed, a comprehensive study based on a numerical approach is proposed in the following in order to identify the optimal use of co-rotating tandem marine propellers even in the presence of cavitation.

The aim of this work is to investigate numerically the steady cavitating flow around corotating tandem propeller by using the RANS method. As the first step, the numerical approach proposed has been validated by applying it on the case of single propeller in both non cavitating and cavitating conditions. After that, tandem propeller is tested on the cavitating and non-cavitating flow and comparison of results was made with the case of single propellers. 


\section{Geometric modelling}

Three-dimensional flow modelling using CFD has been carried out to investigate the appearance of the cavitating flow as function on the operating conditions. Two propeller devices based on the conventional INSEAN E779A, single propeller and tandem co-rotating configuration, have been considered. The main geometrical parameters of theses propellers are summarized in Table 1. According to the study mentioned in reference [11], the propellers used in the tandem geometries have idem diameters and the relative axial displacement between the aft and the forward propeller is equal to 0.2 and 0.6. The angular displacement between the tandem propellers was kept $0^{\circ}$. Figure 1 shows the geometric shape of the INSEAN E779A propeller in single and tandem configurations generated using Gambit.

Table 1 Key design data of the tested propellers

\begin{tabular}{|l|c|l|}
\hline Model name & $\begin{array}{c}\text { INSEAN E779A single } \\
\text { propeller }\end{array}$ & $\begin{array}{c}\text { Tandem co-rotating } \\
\text { propeller }\end{array}$ \\
\hline Blades number & 4 & $(4+4)$ \\
\hline Diameter $(\mathrm{m})$ & 0.22727 & 0.22727 \\
\hline Pitch ratio at 0.7R & 1.1 & $\left(\mathrm{P}_{\text {Fore }} / \mathrm{D}\right)=\left(\mathrm{P}_{\text {Aft }} / \mathrm{D}\right)-0.2$ \\
\hline Expanded area ratio & 0.689 & $(0.689+0.689)$ \\
\hline Skew & $4^{\circ} 48^{\prime}$ & $4^{\circ} 48^{\prime}$ \\
\hline Rake & $4^{\circ} 35^{\prime}$ & $4^{\circ} 35^{\prime}$ \\
\hline
\end{tabular}

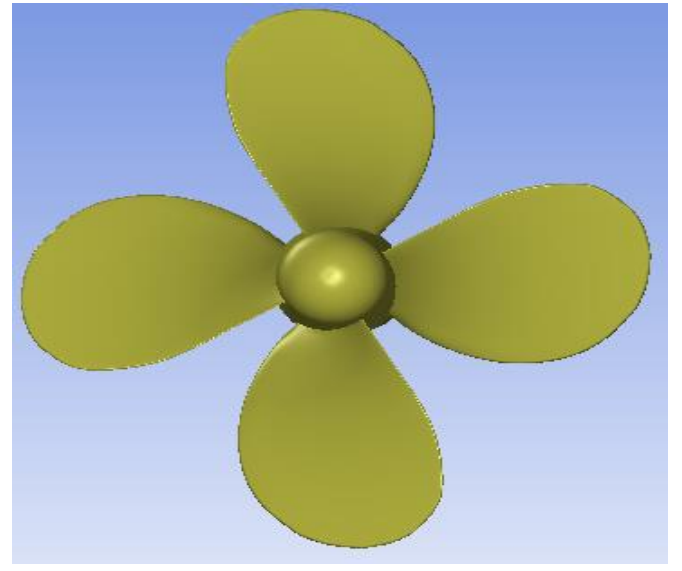

Single INSEAN E779A propeller

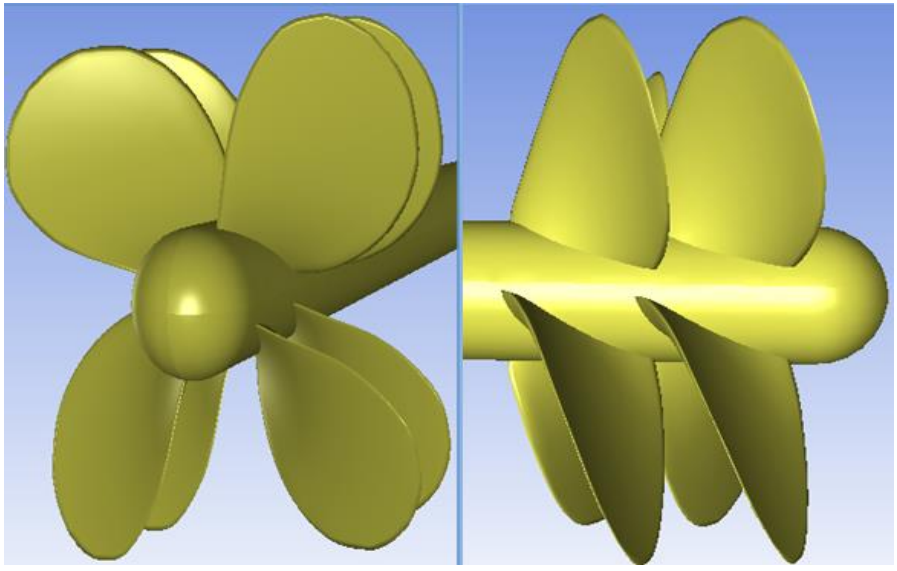

Co-rotating tandem propeller

Fig. 13 D view of tested propellers blades

\section{Mesh generation}

Taking into account the periodicity condition, the computational domain was created for only one blade. The proportions of the domain were chosen according to the studies cited in [14]. Due to the complexity of marine propeller geometry, unstructured tetrahedral mesh has been adopted using the Gambit pre-processor. A mesh refinement zone is defined near the propeller blade. The mesh was generated in such a way that cell sizes near the blade wall were small and increased progressively towards outer boundary. Finally, calculation domain meshed by tetrahedral meshes has been obtained, as shown in Figure 2. In the case of cavitation, the mesh is designed so as not to over-fine the wall (boundary layers) in order to 
avoid too excessive calculation time and agree well with the chosen turbulence model $(\mathrm{K}-\varepsilon$ Standard) as it is reported in [8]. Particular attention was also paid to the control of element skewness to ensure a good quality of the produced mesh. The number of cells thus generated is 903000 equivalent to a number of nodes of 182000 .
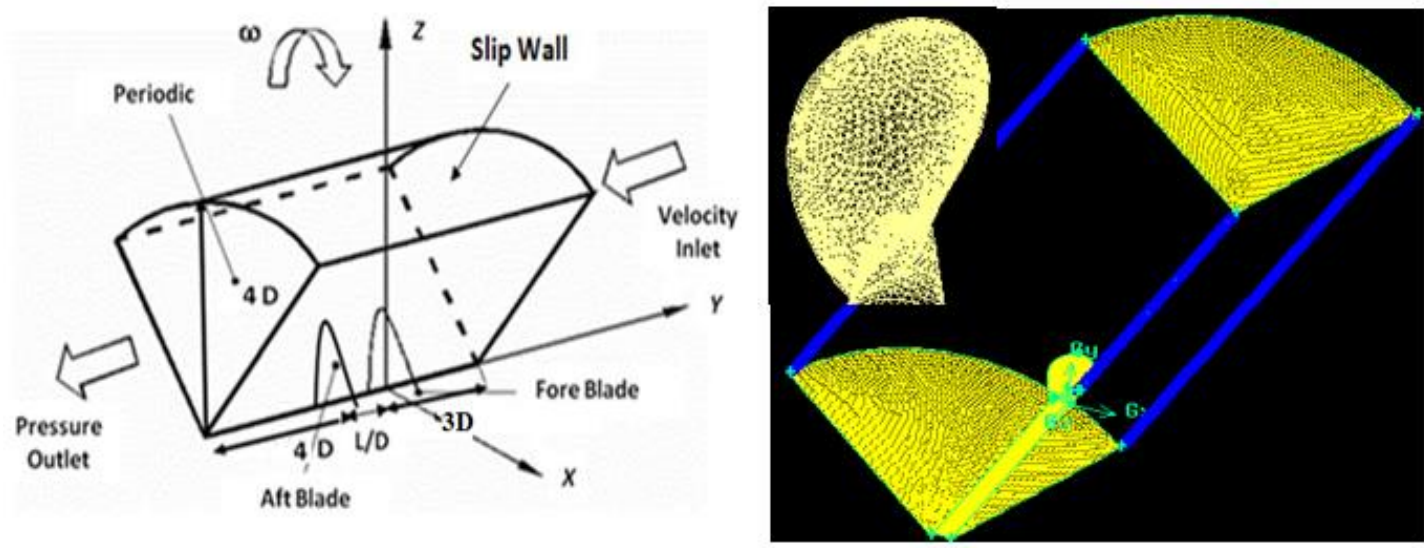

Fig. 2 Boundary condition and mesh over the computational domain

\section{Physical conditions}

Numerical testes are carried out for the case of propeller in open water conditions. A moving reference frame is assigned to the fluid where the rotational speed of propeller is constant. The inlet condition is represented by the axial velocity, while pressure outlet boundary has been adopted as outlet condition. For the cavitating cases, the static outlet pressure is determined by cavitation number.

In this study, calculations are performed using CFD code Fluent and adopting $\mathrm{K}-\varepsilon$ Standard as turbulence model. The SIMPLE algorithm has been adopted and the schemes were all in the second order. Propellers were tested in cavitating conditions by adopting the Singhal cavitation model implemented in code Fluent. Both non-cavitating and cavitating calculations were performed at a rotational speed of $n=36$ rps on single and tandem corotating propeller configurations in a uniform flow.

The first calculation in cavitating flow was carried out on a model of the INSEAN E779A propeller for an advance parameter $\mathrm{J}=0.71$ and for three cavitation numbers $(\sigma=1.763$, $\sigma=2.270$ and $\sigma=2.775$ ). The test conditions were reproduced according to the experimental test carried out in the INSEAN cavitation tunnel [15]. It should be noted that for a given $\mathbf{J}$ leading to a non-cavitating flow, the cavitation can be caused by a decrease in pressure at the outlet while still maintaining the same $\mathrm{J}$.

In the second step, two tandem configurations having respectively a relative axial displacement equal to 0.2 and 0.6 were tested on the cavitating flow for a cavitation number equal 1.763 and an advance parameter $\mathrm{J}=0.71$. These conditions were chosen for a comparison with twin-screw propulsion configuration at loaded conditions. 


\section{Results and discussions}

For the study of co-rotating tandem cavitation, the INSEAN E779A propeller was chosen as a reference due to the availability of experimental data in the literature [16]. In this case, the INSEAN E779A propeller, in single configuration, was first tested and validated in the non-cavitating case.

As a first step, three tetrahedral meshes, different by the number of cells, were generated to test the sensitivity of the solution to the mesh size as resume Table 2 . Computation was made at $\mathrm{J}=0.71$ for the open water performance prediction of the conventional E779 A propeller. Table 3 compares the computed thrust and torque coefficients on the three grids with the experimental values [17]. In non-cavitaing conditions, small discrepancy is observed especially for $K_{Q}$ between the medium and the fine grid. This tendency seems to be common in most of the RANS CFD simulation for marine propellers [8$16-18]$.

Table 2 Details of grid size

\begin{tabular}{|l|l|l|l|}
\hline Grid & $\begin{array}{c}\text { Type of } \\
\text { element }\end{array}$ & Number of cells & $\begin{array}{c}\text { Number of } \\
\text { nodes }\end{array}$ \\
\hline Coarse & Tetrahedral & 303721 & 60236 \\
\hline Medium & Tetrahedral & 641755 & 122484 \\
\hline Fine & Tetrahedral & 1294365 & 241077 \\
\hline
\end{tabular}

Table 3 Comparison of predicted and the experimental values of $\mathrm{K}_{\mathrm{T}}$ and $\mathrm{K}_{\mathrm{Q}}$ for the tested grids

\begin{tabular}{|l|l|l|l|l|l|}
\cline { 3 - 6 } \multicolumn{2}{c|}{} & \multicolumn{2}{c|}{ Numerical Results } & \multicolumn{2}{c|}{ Exp. Data } \\
\hline Grid & $\mathbf{J}$ & $\mathbf{K}_{\mathbf{T}}$ & $\mathbf{1 0 K}_{\mathbf{Q}}$ & $\mathbf{K}_{\mathbf{T}}$ & $\mathbf{1 0 K}_{\mathbf{Q}}$ \\
\hline Coarse & 0.71 & 0.232 & 0.443 & 0,238 & 0.429 \\
\hline Medium & 0.71 & 0.233 & 0.442 & 0.238 & 0.429 \\
\hline Fine & 0.71 & 0.231 & 0.441 & 0.238 & 0.429 \\
\hline
\end{tabular}

For the next calculations, single and tandem co-rotating propeller, the rotational speed of propellers is kept constant and equal to $n=36 \mathrm{rps}$. The inlet velocity is changing in such a way to obtain the advance coefficient between $\mathrm{J}=0.3$ and $\mathrm{J}=1.1$.

The results of this simulation are illustrated in Figure 3 and Figure 4. As shown in Figure 3 good agreement between the experimental and numerical data for the tested $\mathbf{J}$ values is obtained for the E779A propeller. However, the error slightly increases for the low values of $\mathrm{J}, 10 \%$ for the $\mathrm{K}_{\mathrm{T}}$ coefficient and $6 \%$ for the $\mathrm{K}_{\mathrm{Q}}$ coefficient.

Figure 4 illustrates the performance of the $(\mathrm{L} / \mathrm{D}=0.6)$ tandem compared to doubled INSEAN E779A propeller. This representation makes it possible to highlight the advantages of using the tandem compared to the double conventional propeller in a ship with twin-screw propulsion.

From the result exam, it is clearly observed that from $J=1$ the tandem provides a higher thrust than that of two separate propellers accompanied by a slight increase in torque. Moreover, the efficiency of the two technological solutions become equal at $\mathrm{J}=1.05$ after which the tandem maintains its supremacy in thrust and torque, about $16 \%$ increase. 


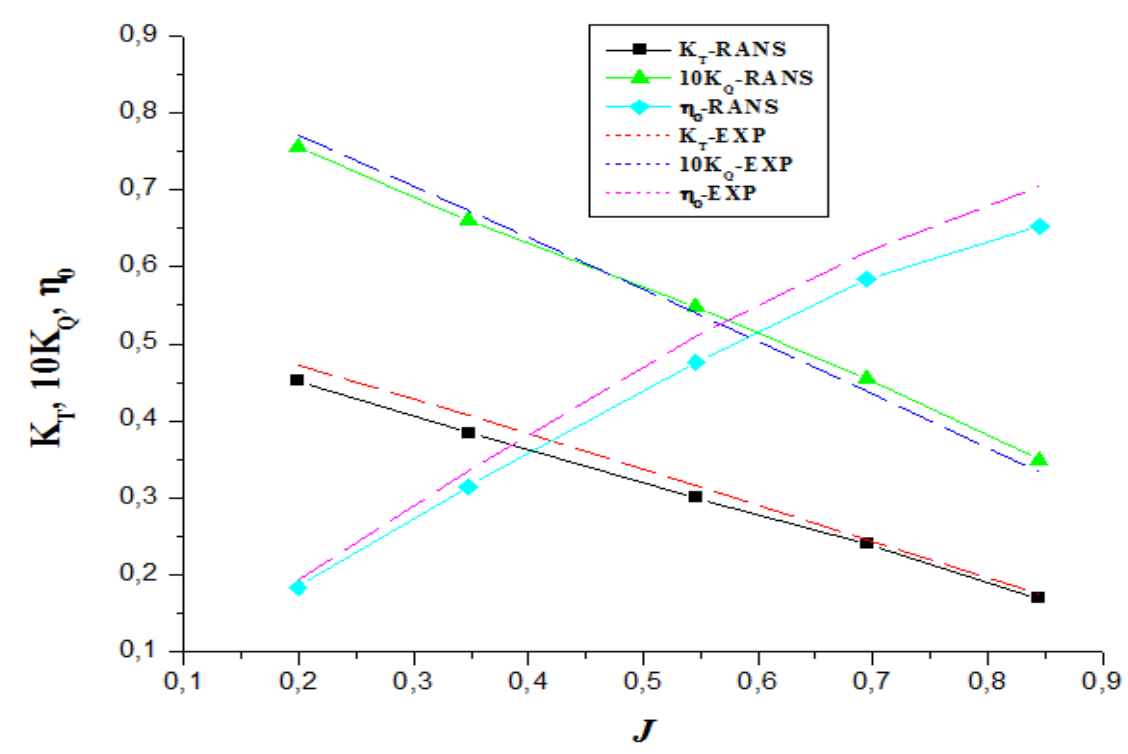

Fig. 3 Validation of the open water performances of the INSEAN E779A propeller

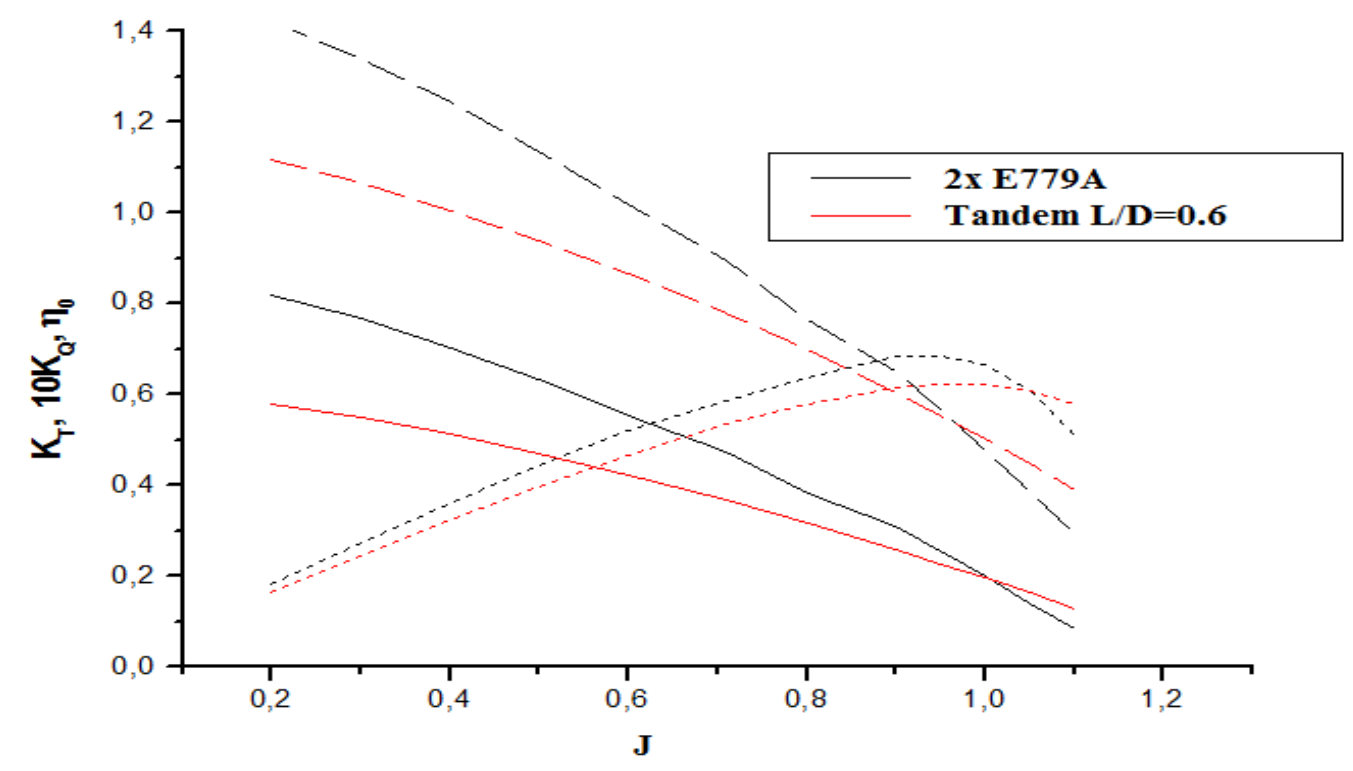

Fig. 4 Hydrodynamic characteristics of the doubled E779A propeller and co-rotating tandem $(\mathrm{L} / \mathrm{D}=0.6)$

In this part, the INSEAN E779A propeller was tested for three more or less pronounced cavitation cases corresponding to a rotational speed $n=36$ rps. The calculations have been performed for three cavitation number and $\mathrm{J}=0.71$. Results of open water tests were represented in terms of thrust, torque and efficiency coefficients and compared to the available experimental data as it is summarized in Table 4. Based on these results, the simulation of the cavitating flow using the numerical approach proposed in this study is globally satisfactory despite a slight difference being observed for all the coefficients. This fact has also been observed by other authors [15-16] who have concluded that numerical cavitation models reproduce the hydrodynamic coefficients more or less correctly and that an improvement of these models is necessary for the refinement of the results. 
Table 4 Comparison of predicted and the experimental values of $K_{T}, K_{Q}$ and $\eta_{0}$ in cavitating flow

\begin{tabular}{|l|l|l|l|l|l|l|l|}
\cline { 3 - 8 } \multicolumn{2}{l|}{} & \multicolumn{3}{c|}{ Numerical Results } & \multicolumn{3}{|c|}{ Exp. Data } \\
\hline$\sigma$ & $\mathrm{J}$ & $\mathrm{K}_{\mathrm{T}}$ & $10 \mathrm{~K}_{\mathrm{Q}}$ & $\eta_{0}$ & $\mathrm{~K}_{\mathrm{T}}$ & $10 \mathrm{~K}_{\mathrm{Q}}$ & $\eta_{0}$ \\
\hline 1.763 & 0.71 & 0.250 & 0.448 & 0.619 & 0.255 & 0.460 & 0.626 \\
\hline 2.270 & 0.71 & 0.250 & 0.449 & 0.602 & 0.255 & 0.461 & 0.625 \\
\hline 2.775 & 0.71 & 0.251 & 0.450 & 0.604 & 0.256 & 0.464 & 0.623 \\
\hline
\end{tabular}

Figure 5 illustrates a comparison of the cavitating area on the propeller blades obtained numerically with the experimental visualizations for the three cavitation numbers [14]. It should be noted that the surface of cavitation area increases with the decrease in the cavitation number which is obvious and it is confirmed experimentally and numerically. Furthermore, the cavitation seems to be very developed at the blade tip and the calculation results are in good agreement with the experimental visualization. However, the cavitation results obtained experimentally shows a slightly different pattern of the flow compared to the numerical results. Indeed, it is observed in Figure 5 that cavitation fellows the tip vortex trajectory. Unfortunately, the numerical predictions do not reproduce it faithfully. It should be noted that this fact is observed in all previous numerical studies devoted to cavitation on the same propeller [16-17-19]. The reasons given seem to be related to the quality of the mesh in these regions [19] and to the theoretical model of cavitation adopted for the simulation. 

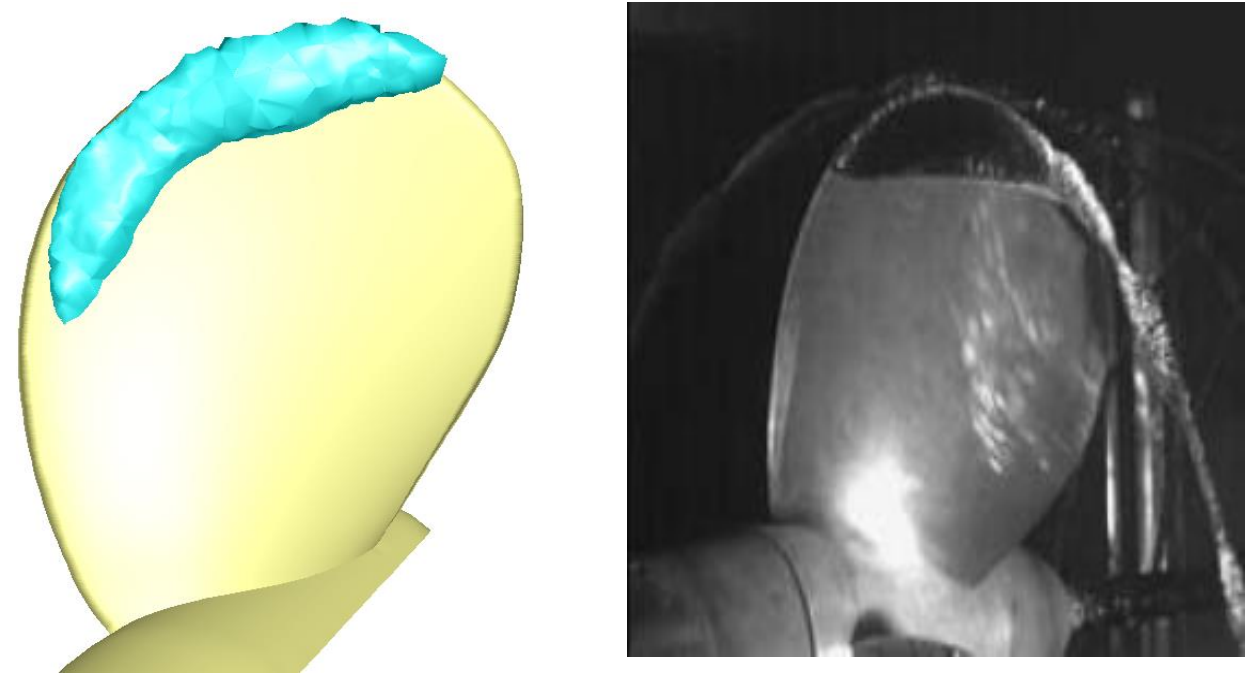

$\sigma=1.763$
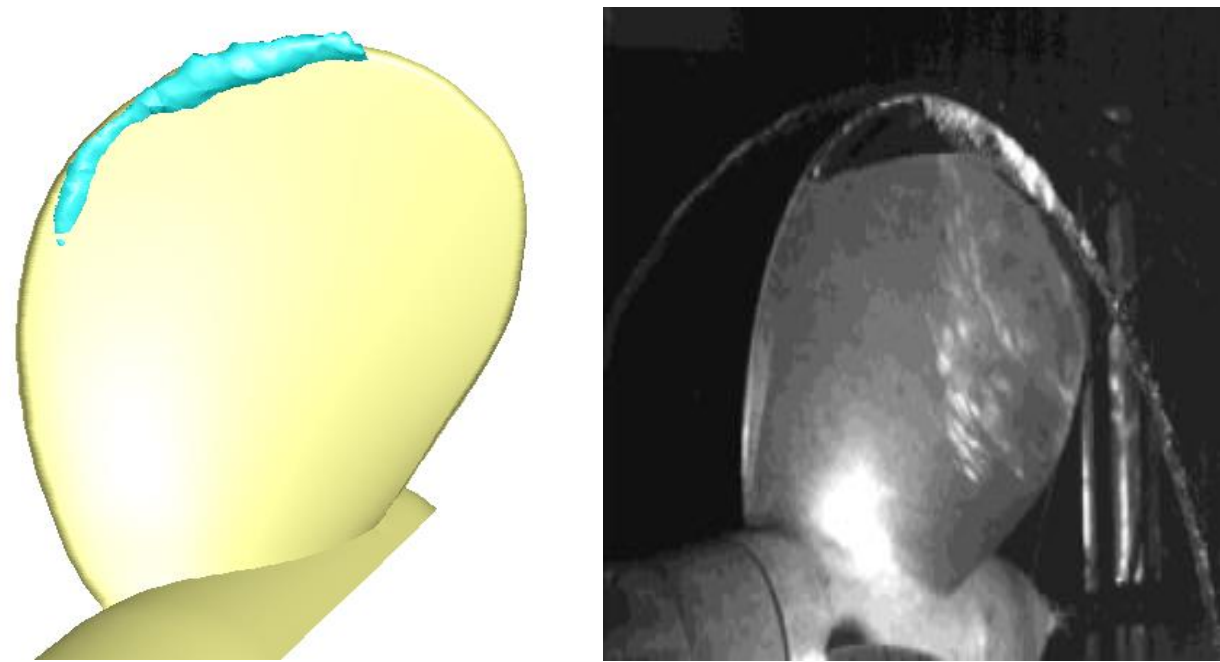

$\sigma=2.270$
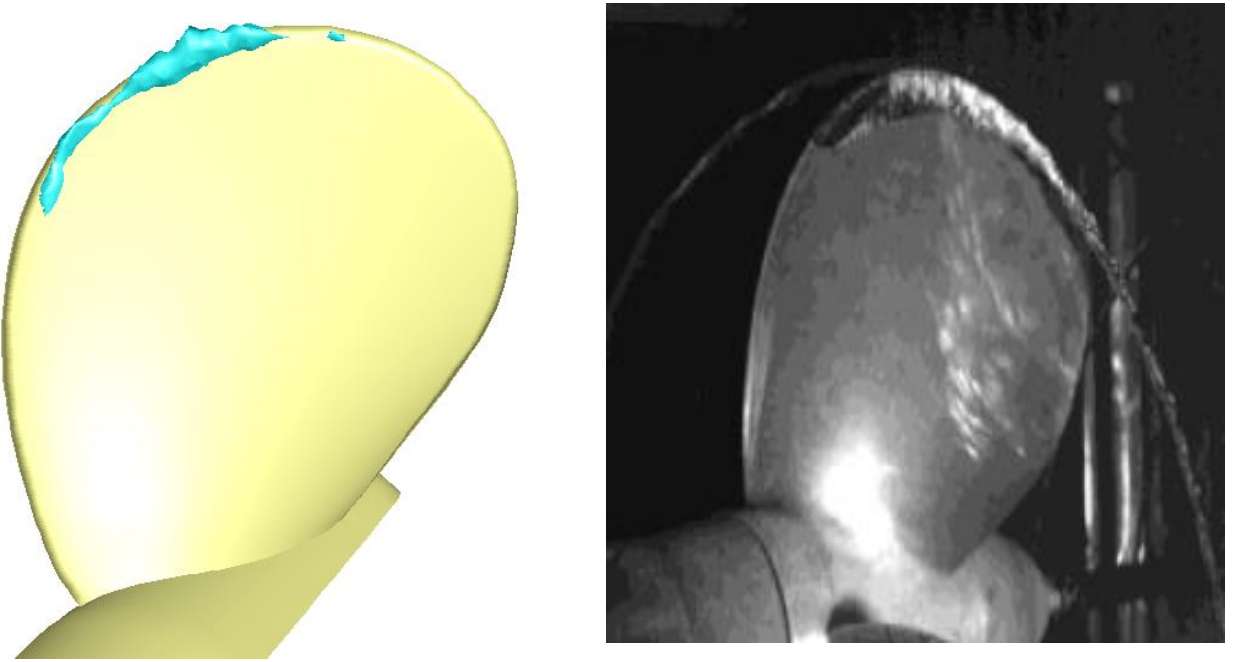

$\sigma=2.775$

Fig. 5 Comparison of numerical and experimental visualizations of cavitation development on the E779A propeller 
The tandem co-rotating propeller was also studied in the case of cavitating flow. In this part, a pair of the conventional E779A propeller fitted in tandem co-rotating configuration is tested. Tandem propeller with identical diameters are spaced axially by a distance $\mathrm{L} / \mathrm{D}=0.6$. The cavitation simulations are performed for a cavitation number of 1.763 at the same rotational speed and advance parameter. These operational conditions were chosen for a comparison with single propeller behavior in similar loaded conditions. Table 5 shows the detail of the tandem hydrodynamic coefficients, obtained numerically, with and without cavitation. It is obvious that cavitation causes a decrease of marine propellers performances. This fact has been confirmed through the analysis of these results although the observed decrease of the $\mathrm{K}_{\mathrm{T}}$ and $\mathrm{K}_{\mathrm{Q}}$ coefficients is minimal. In addition, the unequal contributions of thrust and torque of the tandem aft and fore propellers, observed in the case of non-cavitating flow, are maintained even in the presence of cavitation.

Table 5 Computational estimation of the hydrodynamic characteristics of tandem propeller in cavitating and non-cavitating flow for $\mathrm{J}=0.71$

\begin{tabular}{|l|r|r|r|r|r|r|}
\cline { 2 - 7 } \multicolumn{1}{c|}{} & \multicolumn{3}{c|}{ Non-cavitation } & \multicolumn{3}{c|}{ Cavitation } \\
\cline { 2 - 7 } \multicolumn{1}{c|}{} & $\mathrm{K}_{\mathrm{T}}$ & $10 \mathrm{~K}_{\mathrm{Q}}$ & $\eta_{0}$ & $\mathrm{~K}_{\mathrm{T}}$ & $10 \mathrm{~K}_{\mathrm{Q}}$ & $\eta_{0}$ \\
\hline Advance parameter & \multicolumn{7}{c|}{$\mathrm{J}=0.71$} \\
\hline Fore propeller & 0.240 & 0.436 & 0.476 & 0.233 & 0.427 & 0.471 \\
\hline Aft propeller & 0.143 & 0.338 & 0.621 & 0.137 & 0.330 & 0.615 \\
\hline Tandem & 0.383 & 0.774 & 0.557 & 0.370 & 0.757 & 0.552 \\
\hline
\end{tabular}

This behavior of the tandem propellers is well elucidated by the pressure contours obtained on the blades in the cavitating and non-cavitating case. Indeed, Figure 6 shows the pressure contours on the faces of the two tandem propellers for $\mathrm{J}=0.71$. In the absence of cavitation, the minimum pressure coefficient $\mathrm{C}_{\mathrm{Pmin}}$ recorded on the upper surface of the aft propeller blade, equal to -1.84 , assumes that cavitation would be more intense on this face. Nevertheless, the depression surface is rather extended on the back side of the fore propeller which induces a greater cavitation area on this face. This is obviously well confirmed by the pressure contours on the blades in the cavitating case. Moreover, the examination of these contours also reveals the appearance of a limited zone of strong depression in the lower portion of the aft propeller which could be the seat of a cavitation. All these suggestions or predictions are well attested by the visualization of the vapor area on the tandem blades shown in Figure 7.

The development of cavitation on the tandem blades for the advance parameter $\mathrm{J}=0.71$ is shown in Figure 8. Comparing the tandem performances to that of single propeller (Figure 5), maximum cavitation area and vapor fraction are noticed on the single propeller. Results reveal that for the tandem operating case the propellers develop very little cavitation in the back side of the aft propeller localized in the bottom leading edge. This result is justified by the existence of a small suction pressure zone as it is shown in Figure 6. 
Tandem Fore propeller (L/D=0.6), Non-cavitating flow
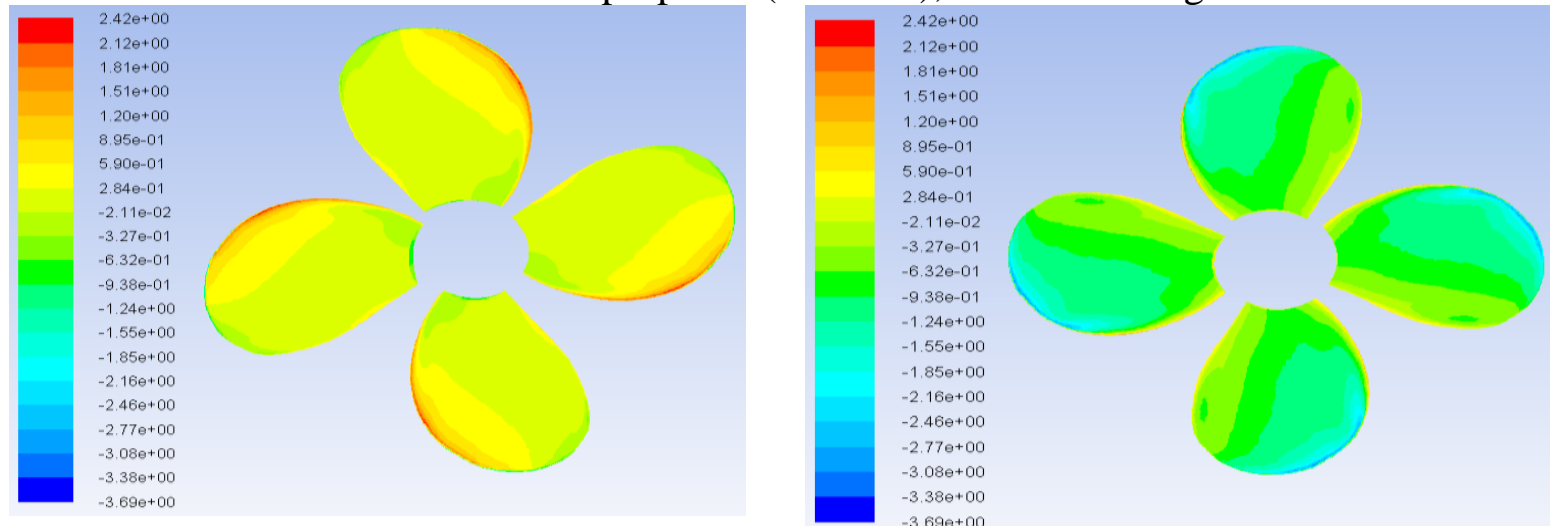

Tandem Aft propeller (L/D=0.6), Non-cavitating flow
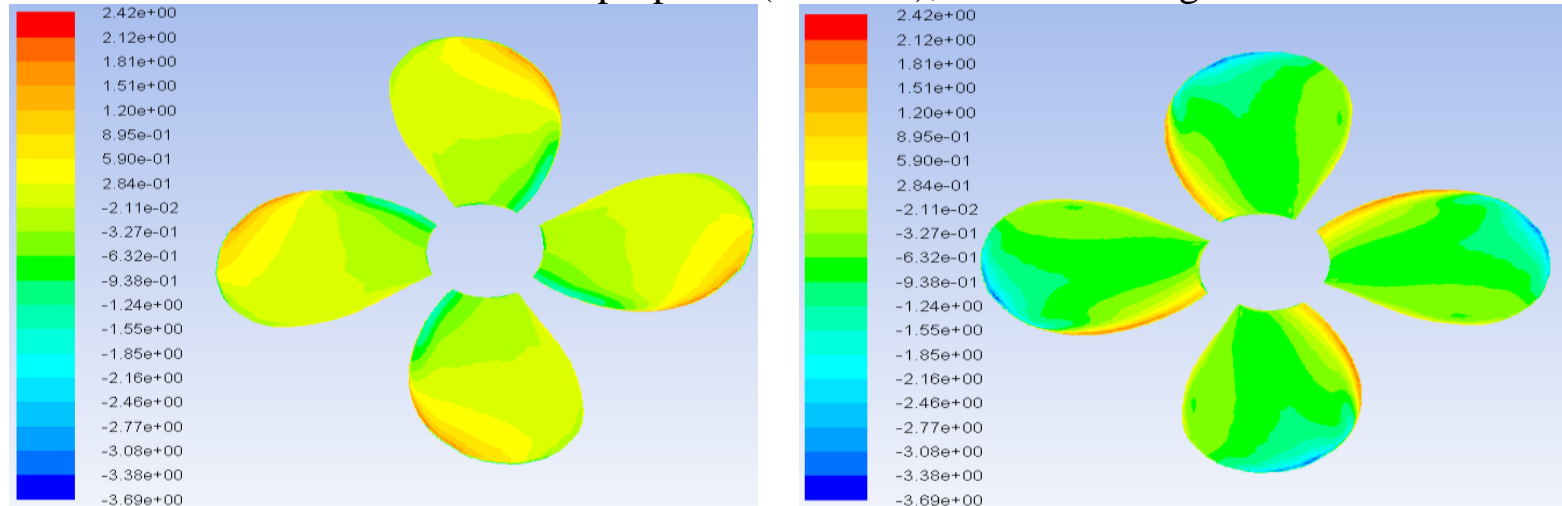

Tandem Fore propeller (L/D=0.6), Cavitating flow
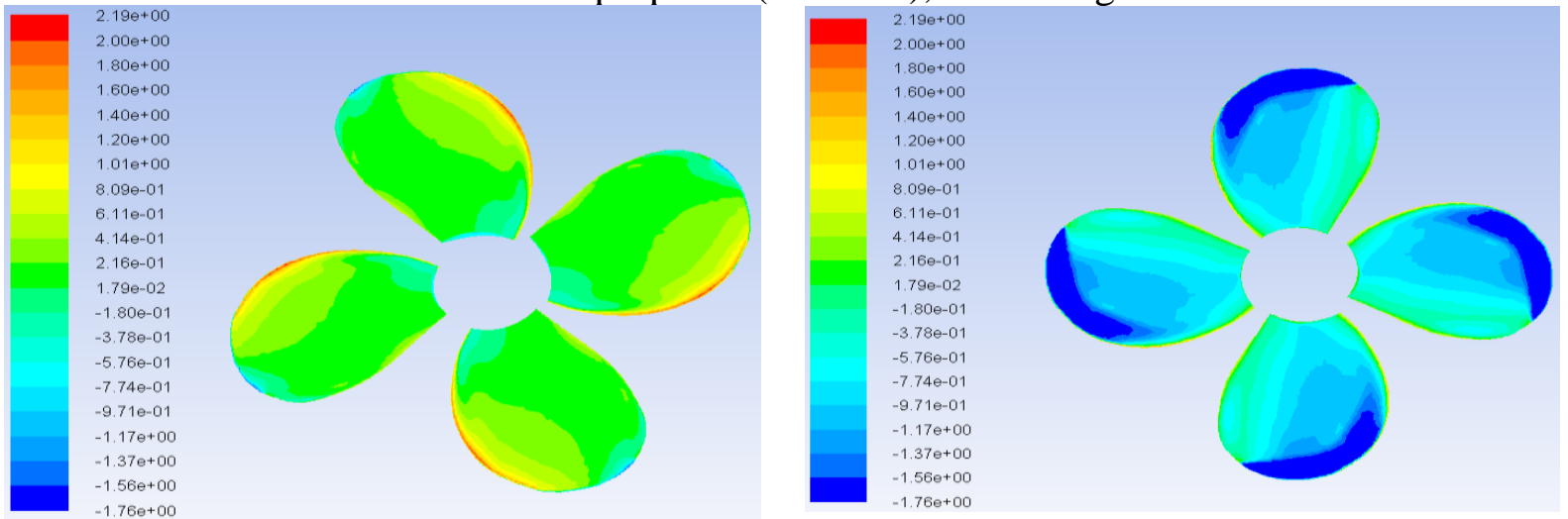

Tandem Aft propeller (L/D=0.6), Cavitating flow

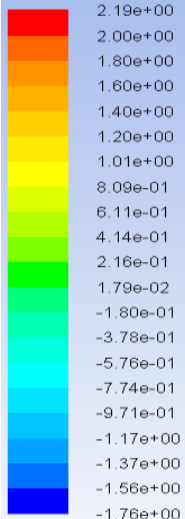

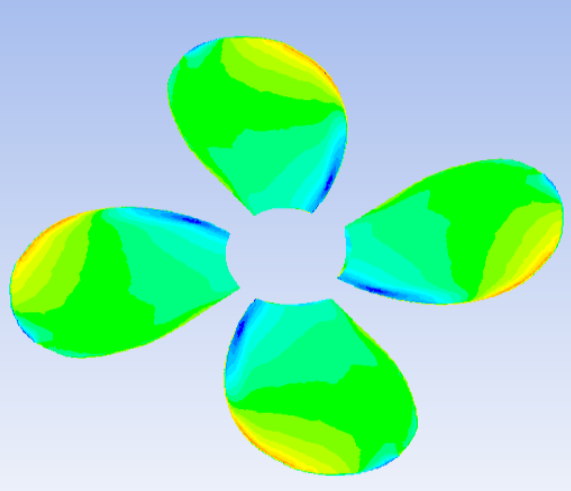

Face side

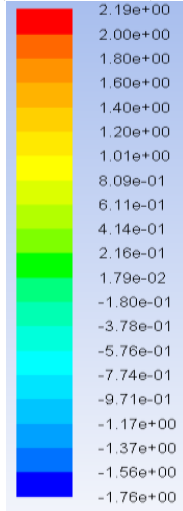

$-1.76 \theta+00$

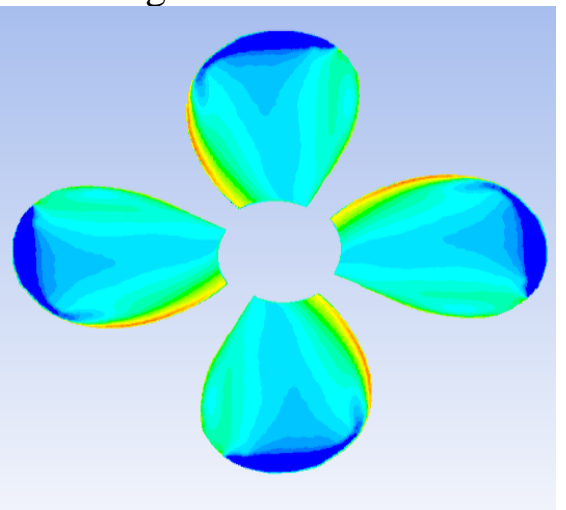

Back side

Fig. 6 Distribution of pressure coefficient on the tandem blades in cavitating and noncavitating flow for $\mathrm{J}=0.71$ 
Tandem Fore propeller $(\mathrm{L} / \mathrm{D}=0.6)$

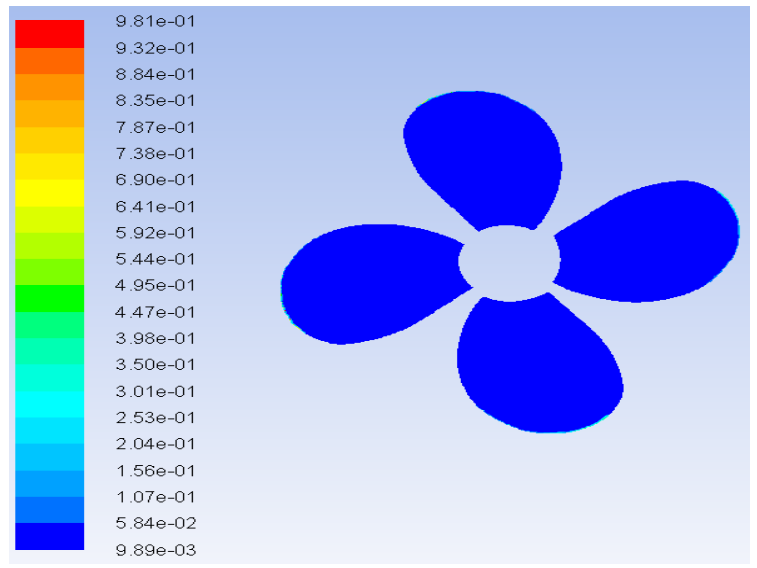

Face side

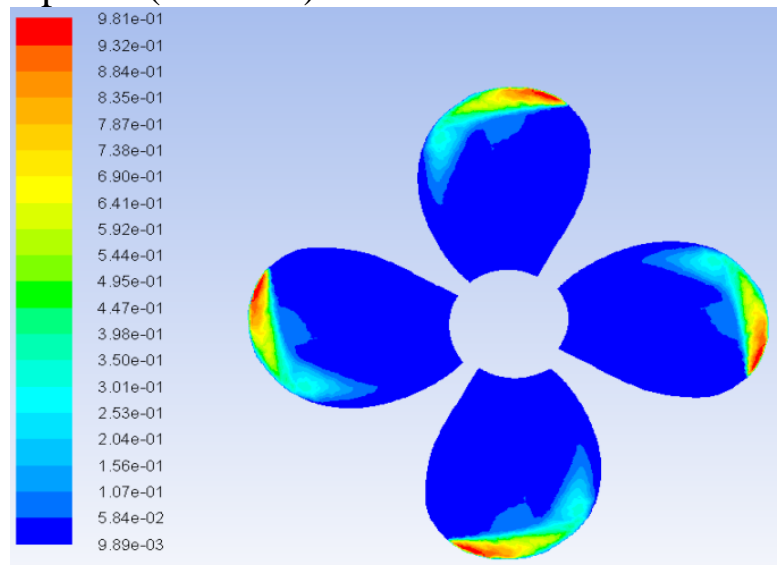

Back side

Tandem Aft propeller (L/D=0.6)

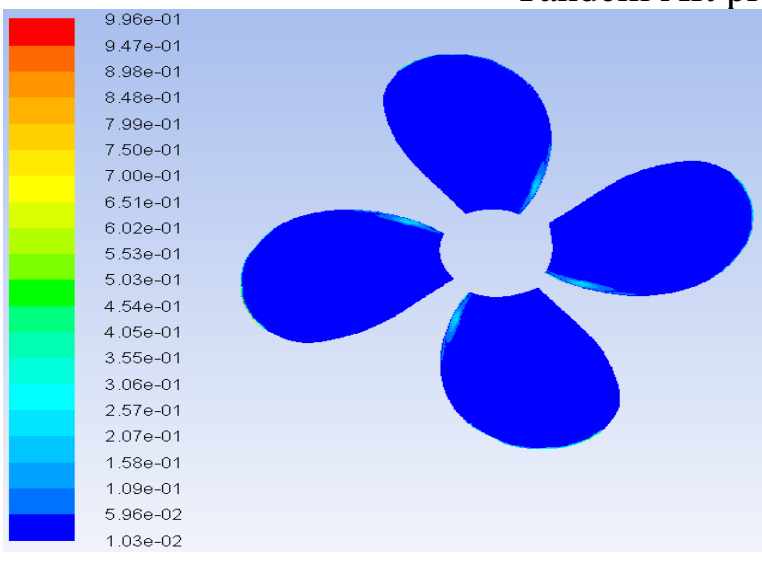

Face side

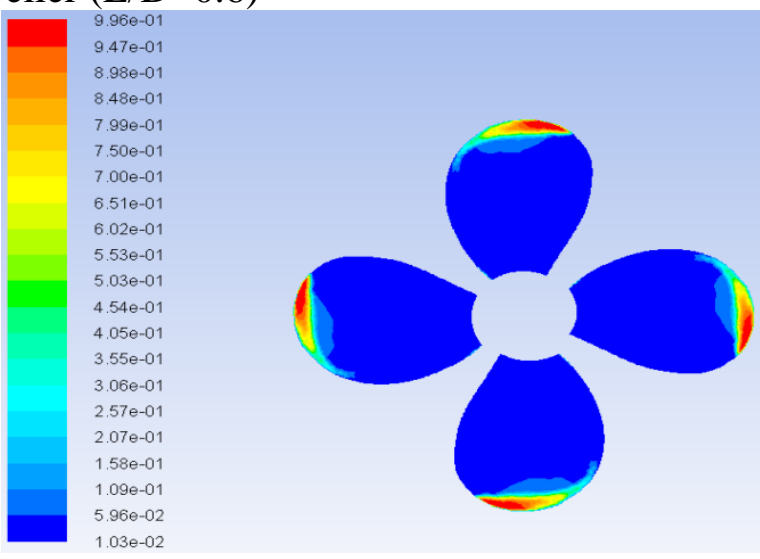

Back side

Fig. 7 Contours of volume fraction on the tandem blades in cavitating flow for $\mathrm{J}=0.71$

Testes of cavitation are also applied for another tandem configuration with an axial displacement ratio equal to $\mathrm{L} / \mathrm{D}=0.2$, usually used for ship equipped with tandem co-rotating device [12-20]. Simulations are conducted in the same operating conditions in order to compare the obtained results at least qualitatively to those reported in reference [12-13]. In this case, calculations are carried out only for one critical cavitation number $(\sigma=1.763)$ and for an advance parameter $J=0.71$. Table 6 resumes open water performances of the tandem $\mathrm{L} / \mathrm{D}=0.2$ in cavitating and non cavitating conditions. It is observed that the fall of the hydrodynamic efficient keeps the same trend as the previous cases. This observation has already been reported in [13-14] which indicates that the extent of cavitation is more pronounced on the fore propeller. In order to diminish the cavitation effect in tandem propellers, authors in [14] suggest that the reduction of the fore propeller diameter could improve the tandem performances in cavitating flow. Otherwise, to achieve the same objective, it is recommended in reference [13-21] to reduce the fore propeller pitch and increase the aft one. These two affirmations suppose that pitch and diameter ratios adjustment promise the optimal tandem design. 
Table 6 Computational estimation of the hydrodynamic characteristics of tandem $\mathrm{L} / \mathrm{D}=0.2$ propeller

\begin{tabular}{|c|c|c|c|c|c|c|}
\hline & \multicolumn{3}{|c|}{ Non-cavitation } & \multicolumn{3}{|c|}{ Cavitation } \\
\hline & $\mathrm{K}_{\mathrm{T}}$ & $10 \mathrm{~K}_{\mathrm{Q}}$ & $\eta_{0}$ & $\mathrm{~K}_{\mathrm{T}}$ & $10 \mathrm{~K}_{\mathrm{Q}}$ & $\eta_{0}$ \\
\hline Advance parameter & \multicolumn{6}{|c|}{$\mathrm{J}=0.71$} \\
\hline Fore propeller & 0.147 & 0.341 & 0.486 & 0.161 & 0.372 & 0.490 \\
\hline Aft propeller & 0.195 & 0.361 & 0.611 & 0.191 & 0.359 & 0.609 \\
\hline Tandem & 0.342 & 0.702 & 0.550 & 0.352 & 0.727 & 0.549 \\
\hline
\end{tabular}

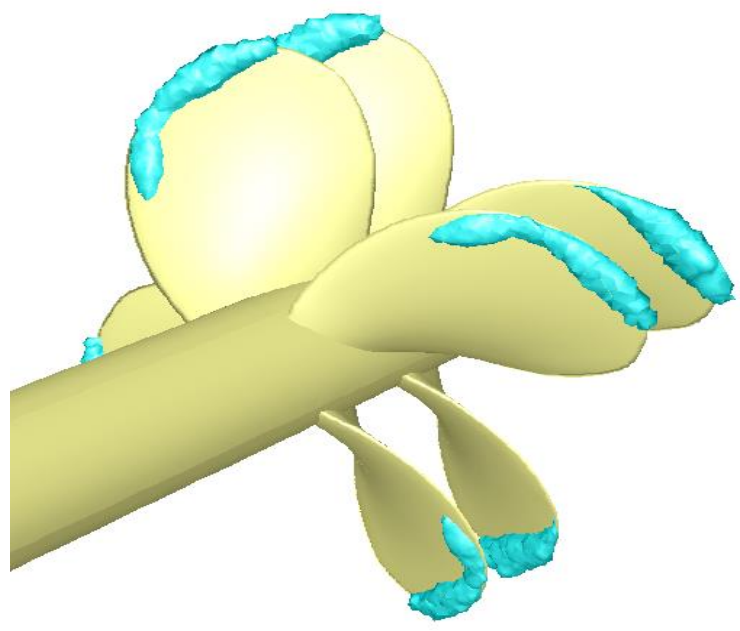

Front view

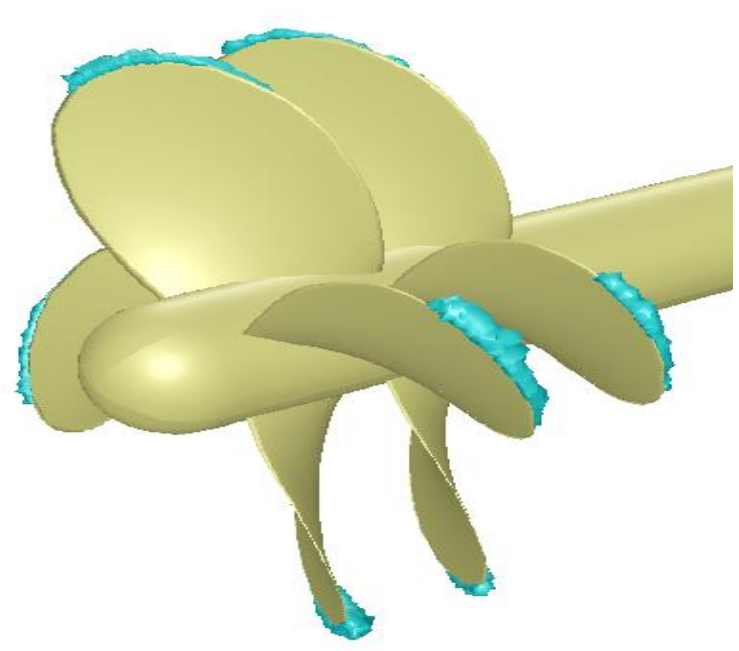

Rear view

Fig. 8 Development of cavities on the $\mathrm{L} / \mathrm{D}=0.2$ tandem blades for $\mathrm{J}=0.71$

In order to bring the advantage of replacing conventional propeller by tandem solution even in cavitating conditions, tandem geometries $(\mathrm{L} / \mathrm{D}=0.6$ and $\mathrm{L} / \mathrm{D}=0.2)$ are tested at theirs operational conditions where the tandem propeller give the double single propeller thrust coefficient $\left(\mathrm{K}_{\mathrm{T} \text { Tandem }}=2 \mathrm{~K}_{\mathrm{T} \text { Single }}\right.$ ). Using $\mathrm{K}_{\mathrm{T}}$ curve (Figure 4$)$ and assuming that the single propeller is tested for $\mathrm{J}=0.71$, equal thrust condition is realized for tandem propellers $(\mathrm{L} / \mathrm{D}=0.6)$ in cavitating and non-cavitating cases at the corresponding advance coefficient $\mathrm{J}=0.5$. By the same way, the advance coefficient for tandem propellers $(\mathrm{L} / \mathrm{D}=0.2)$ is determined equal to $J=0.4$. All simulations are performed for the same rotational speed, $n=36$ rps, and for the same cavitation number $\sigma=1.763$. The hydrodynamic coefficients results are presented in table 7 where is observed, in non-cavitating case, a decrease of tandem's advance parameter compared to twin-screw propeller solution. Also, to conserve the same thrust by maintaining rotational speed and propeller diameter constants, the advance velocity diminishes in the case of tandem configuration between 35 and $40 \%$. While the absorbed power remains slightly lower for tandem configuration, about $80 \%$. In cavitation case, a small decrease of $\mathrm{K}_{\mathrm{T}}$, about $6 \%$, is recorded for tandem propellers whilst the $\mathrm{K}_{\mathrm{Q}}$ increase slightly up to $3 \%$ compared to the twin-screw configuration.

The cavitation areas on tandem propellers are presented in Figure 9. As it is clearly seen, the fore propeller exhibits more developed cavitation area than the aft propeller due probably to the difference of $\mathrm{K}_{\mathrm{T}}$ of these two propellers. However, the fall of $\mathrm{K}_{\mathrm{T}}$ coefficient is approximatively the same on the tandem propellers. Furthermore, the cavitation on the fore 
propeller covers up to $30 \%$ of the propeller area whilst is only about $15 \%$ on the twin propeller configuration.

Table 7 Hydrodynamic characteristics of tandem propellers in cavitating and non-cavitating conditions at the same trust coefficient

\begin{tabular}{|c|r|r|r|r|r|r|}
\cline { 2 - 7 } \multicolumn{1}{c|}{} & \multicolumn{2}{c|}{ Non-cavitation } & \multicolumn{3}{c|}{ Cavitation } \\
\cline { 2 - 7 } & \multicolumn{7}{c|}{$\mathrm{K}_{\mathrm{T}}$} & $10 \mathrm{~K}_{\mathrm{Q}}$ & $\eta_{0}$ & $\mathrm{~K}_{\mathrm{T}}$ & $10 \mathrm{~K}_{\mathrm{Q}}$ & $\eta_{0}$ \\
\hline \multicolumn{7}{|c|}{$\mathbf{L} / \mathbf{D = 0 . 6}, \mathbf{J}=\mathbf{0 . 5}$} \\
\hline Fore propeller & 0.315 & 0.544 & 0.445 & 0.307 & 0.545 & 0.433 \\
\hline Aft propeller & 0.151 & 0.348 & 0.321 & 0.141 & 0.331 & 0.313 \\
\hline Tandem & 0.466 & 0.892 & 0.396 & 0.448 & 0.876 & 0.386 \\
\hline \multicolumn{7}{|c|}{$\mathbf{L} / \mathbf{D}=\mathbf{0 . 2}, \mathbf{J}=\mathbf{0 . 4}$} \\
\hline Fore propeller & 0.316 & 0.538 & 0.449 & 0.299 & 0.529 & 0.433 \\
\hline Aft propeller & 0.150 & 0.352 & 0.314 & 0.149 & 0.350 & 0.313 \\
\hline Tandem & 0.466 & 0.890 & 0.394 & 0.448 & 0.879 & 0.386 \\
\hline
\end{tabular}

Tandem $(\mathrm{L} / \mathrm{D}=0.6), \mathrm{J}=0.5$

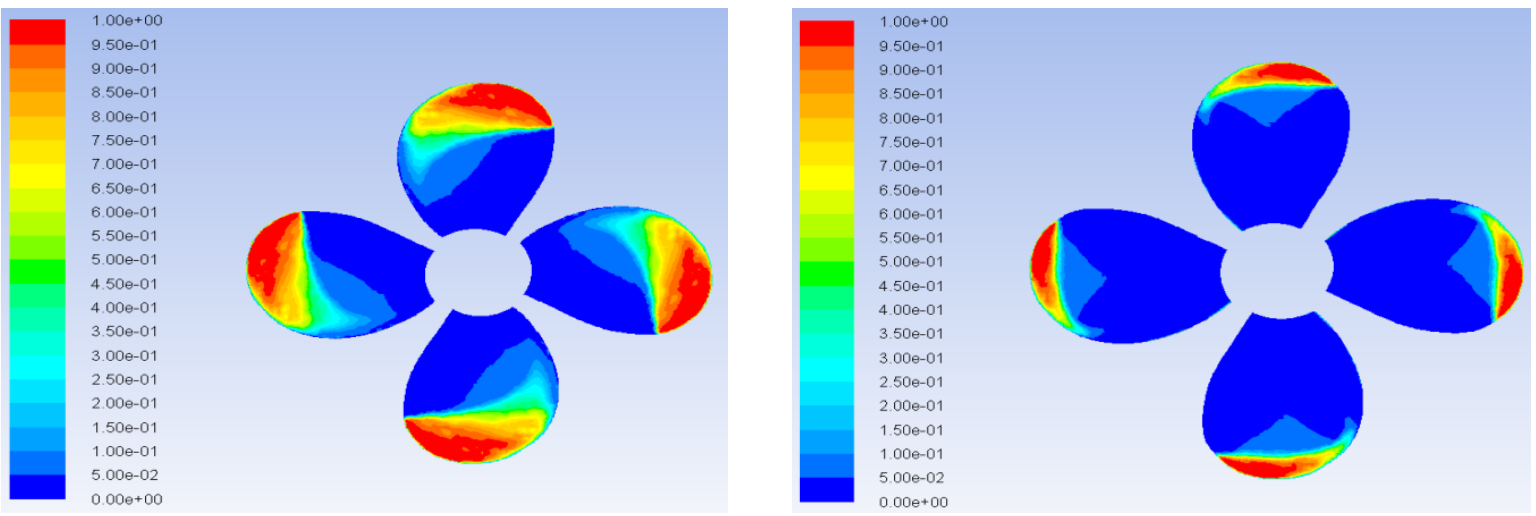

Tandem propeller $(\mathrm{L} / \mathrm{D}=0.2), \mathrm{J}=0.4$

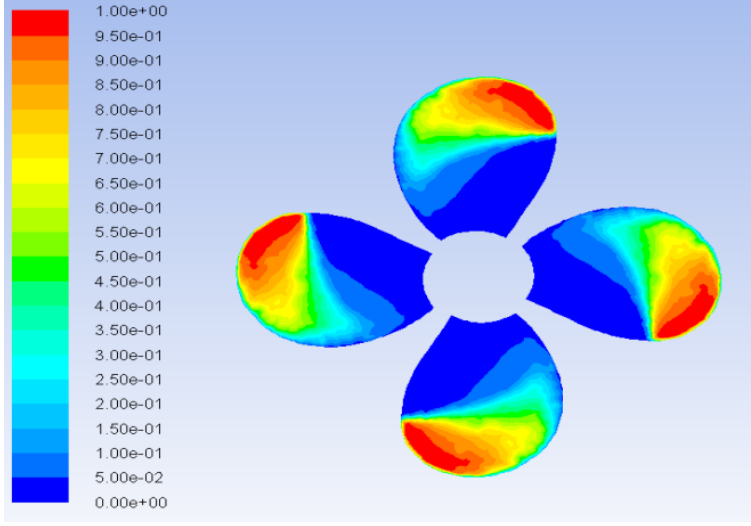

Fore propeller

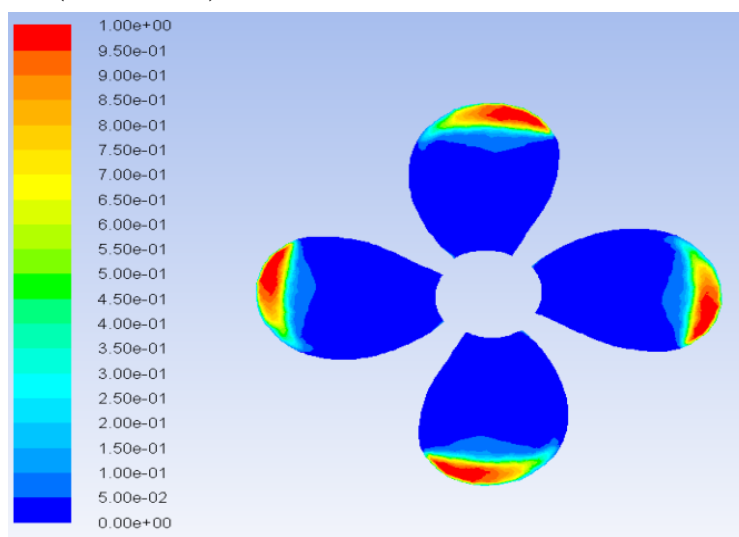

Aft propeller

Fig. 9 Contours of volume fraction on the tandem blades for $\sigma=1.763$ 


\section{Conclusion}

In this work numerical simulations have been carried out to study the conventional INSEAN E779A propeller cavitation in single and tandem configuration. Numerical simulation has been successfully developed for INSEAN Propeller E779A in non-cavitating and cavitating flows where the computed axial thrust and torque are in good agreement with experimental data. Also, the cavitation model used in this study responds faithfully to the change of cavitation number. However, this model fails to reproduce suitably all the cavitation types which can possibly appear.

For the tandem co-rotating configuration, results show that the propellers behavior in cavitating flow is qualitatively well predicted and the cavitation area is more pronounced on the fore propeller comparing to the previous experimental studies. Despite the slightly decrease in the tandem efficient for the case of cavitation, the tandem co-rotating propeller confirms its utility in high loaded conditions.

\section{Acknowledgments}

Authors express their sincere thanks to the INSEAN, and in particular Dr. Francesco Salvatore, for providing the geometry and the experimental measurements of the E779A propeller.

\section{Nomenclature}

$\begin{array}{ll}\mathrm{D} & \text { Propeller diameter } \\ \mathrm{Z} & \text { Blade number } \\ \mathrm{P} / \mathrm{D} & \text { Propeller pitch ratio } \\ \mathrm{L} / \mathrm{D} & \text { Relative axial displacement } \\ \mathrm{C}_{\mathrm{Pmin}} & \text { Pressure coefficient } \\ \sigma & \text { Cavitation number } \\ \mathrm{n} & \text { Number of propeller revolutions } \\ \mathrm{J} & \text { Advance coefficient } \\ \mathrm{K}_{\mathrm{T}} & \text { Thrust coefficient } \\ \mathrm{K}_{\mathrm{Q}} & \text { Torque coefficient } \\ \eta_{0} & \text { Propeller efficiency in open water }\end{array}$

\section{REFERENCES}

[1] P. A. Fitzsimmons, 1979. "Cavitation induced hull pressure: a comparison of analytical results, ship and model measurements". RINA-Symposium on Propeller Induced Ship Vibration, (December 1979), London.

[2] E. Huse, W. Guoqiang, 1982. "Cavitation induced excitation forces on the hull". Transactions SNAME, Vol.90, pp: 85-109.

[3] Y. Ukon, T. Kudo, H. Kamiriisa, H. Yuasa, 1992. "Correlation studies on propeller cavitation making use of a large cavitation tunnel". Transactions SNAME, Vol.100, pp: 65-92.

[4] J. Friesch, C. Johannsen, H. Payer, 1991. "Measurement of pressure distribution of full scale propellers". SNAME- Proceeding of Propellers/Shafting'91, N.13, pp: 1-15, (17-18 September 1991), Virginia Beach.

[5] S. Mishima, S. A. Kinnas, 1997. " Application of a numerical optimization technique to the design of cavitating propellers in non-uniform flow". Journal of Ship Research, N41, pp: 93-107. 
[6] F. A. Pereira, F. Di Felice, F. Salvatore, 2016. "Propeller cavitation in non-uniform flow and correlation with the near pressure field".. J. Mar. Sci. Eng. (JMSE2016), Vol.70, N4, https://doi.org/10.3390/jmse4040070

[7] Y. Chang, Ch. Hu, J. Tu, Y. Chow, 2010. "Experimental investigation and numerical prediction of cavitation incurred on propeller surfaces". Journal of Hydrodynamics, Vol.22, N5, pp: 722-727, $9^{\text {th }}$ International Conference on Hydrodynamics, (11-15 October), Shanghai, China. https://doi.org/10.1016/S1001-6058(10)60028-5

[8] F. Pereira, F. Salvatore, F. Di Felice, M. Elefante, 2002. "Experimental and numerical investigation of the cavitation pattern on a marine propeller". $24^{\text {th }}$ Symposium on Naval Hydrodynamics, (8-13 July), Fukuoka, Japan.

[9] R. Arazgaldi, A. Hajilouy, B. Farhanieh, 2009. "Experimental and numerical investigation of marine propeller cavitation". Sharif University of Technology, Transaction B: Mechanical Engineering, Vol.16, No6, pp: 525-533.

[10] S. Gaggero, G. Tani, D. Villa, M. Viviani, P. Ausonio, P. Travi, G. Bizzari, F. Serra, 2017. "Efficient and Multi-objective Cavitating Propeller Optimization:An Application to a High-speed Craft". Applied Ocean Research, Vol.64, pp: 31-57. https://doi.org/10.1016/j.apor.2017.01.018

[11] D. Boucetta, O. Imine, 2016." Simulation Numérique de l'Ecoulement autour d'un Tandem d'Hélices Marines". EL MIRA'AT SCIENCES, Revue de Science et technologie, Numéro spécial Ecole Militaire Polytechnique EMP, pp: 04-10.

[12] S. Qin, G. Yunde, 1991. "Tandem Propellers for High Powered Ships". Transaction of RINA, pp: $347-$ 362.

[13] B. J. Hadler, W.B. Morgan, K.A. Mayers, 1964. "Advanced propeller propulsion for high-powered single-screw ships". The Society of Naval Architects and Marine Engineers (SNAME), pp: 231-293.

[14] S. Subhas, V. Saji, S. Ramakrishna, H. N. Das, 2012."CFD analysis of a propeller flow and cavitation". International Journal of Computer Applications, Vol.55, N¹6, pp: 26-33.

[15] D. Q. Li, M. Grekula, P. Lindell, J. Hallander, 2012. "Prediction of cavitation for the INSEAN propeller E779A operating in uniform flow and non-uniform wakes". Proceeding of the Eighth International Symposium on cavitation (CAV2012), pp: 368-373, Doi: 10.3850/978-981-07-2826-7 262.

[16] G. Vaz, D. Hally, T. Huuva, N. Bulten, P. Muller, P. Becchi, J. Herrer, S. Whitworth, R. Macé, A. Korsstrom, 2015. "Cavitating flow calculations for the E779A propeller in open water and behind conditions: code comparison and solution validation". Fourth International Symposium on Marine Propulsors (smp'15), Austin, Texas, USA.

[17] T. Sipilä, T. Siikonen, I. Saisto, J. Martio, H. Reksoprodjo, 2009."Cavitating propeller flows predicted by RANS solver with structured grid and small Reynolds number turbulence model approach". Proceeding of the $7^{\text {th }}$ International Symposium on Cavitation (CAV2009), Nº5, (17-22 August), Ann Arbor, Michigan, USA.

[18] S. Gaggero, D. Villa, 216."Steady Cavitating Propeller Performance by Using OpenFOAM, StarCCM+ and Boundary Element Method". Proc IMechE Part M: Journal of Engineering for the Maritime Environment, Publisher SAGE Publications Ltd, Vol.231, N², pp: 411-440. https://doi.org/10.1177/1475090216644280

[19] F. Salvatore, H. Streckwall, T. Terwisga, 2009. "Propeller cavitation modelling by CFD - results from the VIRTUE 2008 Rome Workshop". First International Symposium on Marine Propulsors, (smp'09), Trondheim, Norway.

[20] T. Koronowicz, Z. Krzemianowshi, T. Tuszkowska, J. A. Szantyr, 2010. "A complete design of tandem co-rotating propellers using the new computer system". Polish Maritime Research, Vol.17, N4 (67), pp: 17-25.

[21] D. Boucetta, O. Imine, 2017. "Impact of some geometrical aspects on the tandem co-rotating propeller hydrodynamics characteristics". BRODOGRADNJA, Vol.68, Issue 1, pp: 107-123, MAR 2017, https://doi.org/10.21278/brod68107

Submitted: $\quad 29.11 .2017$.

Accepted: $\quad 08.01 .2019$.
Boucetta Djahida, djahida.boucetta@yahoo.fr Imine Omar, imine_omar@yahoo.fr Aeronautics and propulsive systems laboratory Department of marine engineering, Faculty of mechanical engineering University of Sciences and Technology of Oran, USTO-MB, Oran, Algeria 